\title{
The Role of Liposuclpture of the Posterior Trunk and Thighs in Combination with Fat Transfer to Buttocks to Improve the Aesthetic Results in Different Ethnic Groups
}

\author{
NADER G. ELMELEGY, M.D. and AHMED M. HEGAZY, M.R.C.S., M.D. \\ The Department of Plastic \& Reconstructive Surgery, Faculty of Medicine, Tanta University, Tanta, Egypt
}

\begin{abstract}
Introduction: Plastic surgeons all over the world are challenged with a dramatically increased public interest and demand for aesthetic gluteal contouring surgery. The authors introduce a comprehensive, easy and versatile method for the assessment of "Gluteal-Related Aesthetic Subunits". This method works as a tool to treat the variety of differences in patients' racial body morphology, personal preferences and ethnic related demands, thus improving the results of gluteal aesthetic surgery.
\end{abstract}

Patients and Methods: This is a comparative study of two groups of patients.

In Group (A) patients, the aesthetic assessment and planning for liposuction and fat transfer to the buttocks was performed according to the criteria suggested by Centeno (i.e., each buttock was considered as a single aesthetic subunit that has no subdivisions), and liposuction was performed according to the traditional method. In Group (B) patients, the aesthetic assessment and planning for liposuction fat transfer to the buttocks was performed according to the criteria suggested by the authors, and liposuction was performed according to the new principles of the high-definition liposuction method.

Results: There were significant improvements in the aesthetic results and in the patients' satisfaction as well as a lower rate of complications in Group (B) compared to Group (A).

Conclusion: The authors of this work believe that this new analytical tool is a valuable step forward to help achieve results that are more satisfying to patients due to its simplicity and versatility to meet the needs of a variety of patients with different racial body characteristics and personal demands.

Key Words: Fat transfer - Buttock augmentation by fatgluteal augmentation - buttock augmentation gluteal enhancement - fat transfer.

Level of evidence: A comparative non-randomized study (level II).

\section{INTRODUCTION}

Plastic surgeons all over the world are challenged with a dramatically increased public interest and demand for aesthetic gluteal contouring surgery.
This growing interest may be explained by global cultural interaction, the evolution of body contouring techniques, and the physical appearance of aesthetic and fashion idols. In this work, the authors introduce a comprehensive yet easy and versatile method for the assessment of "Gluteal-Related Aesthetic Subunits". This method works as a tool to treat the variety of differences in patients' racial body morphology, personal preferences, cultural and ethnic related demands, thus improving the results of gluteal aesthetic surgery.

\section{Historical backgrounds:}

The value of an aesthetically attractive gluteal region has been dated as early as recorded history. The ancient Greeks described beautiful women by the term "callipygian" (derived from calli, i.e. beautiful, and pyge, i.e. buttocks) [1]. The ancient Arabs in the medieval ages valued beautiful buttocks that were harmonious with an attractive back and a narrow waist when they praised a woman's beauty. They described beautiful women's waists and buttocks in the following song lyrics: "Her buttocks quiver when she walks; her back is like a willow branch, her waist is slim" [2]. Across cultures, generations, and ethnicities, a wellprojected full buttock with a narrow waist (hourglass figure) symbolized female reproductive potential and physical health [3]. The well-developed buttock is a trait exclusive to humans that contributes to the vertical posture along with the lumbosacral curve [1].

The earliest attempts of gluteal augmentation using implants were made in 1969. The surgeons used breast implants, but the results were frustrating regarding the complications and aesthetic outcomes, which led to the need for better techniques $[\mathbf{1 , 4 , 5}$. Currently, plastic surgeons have numerous techniques for gluteal enhancement that can be broadly classified into three categories, including the use 
of implants (subfacial, submuscular and intramuscular placements), autologous fat transfer and autologous flap augmentation combined with circumferential body lift [6-11].

There is growing advocacy for autologous fat transfer techniques for gluteal contouring among surgeons due to its reported safety, flexibility and long-lasting results. Fat transfer techniques are modified continuously to enhance safety and aesthetic results $[\mathbf{6}, \mathbf{1 2}]$. The recent popularity of body contouring surgeries after massive weight loss led to the development of techniques for gluteal contouring using combinations of autologous flaps, fat transfer or implants along with circumferential body lift $[\mathbf{9 , 1 1 , 1 3 ]}$.

\section{Aesthetic analysis of the gluteal region:}

Like all body contouring surgeries, gluteal enhancement requires proper planning.

For appropriate planning, it is essential to carefully identify the aesthetic characteristics of the gluteal area and the surrounding related body areas. A proper scientific method to define the beautiful gluteal area was not reported until the work of Cuenca-Guerra and Quezada reported the most recognizable features of the aesthetically pleasing gluteal area from the posterior and side views according to their study [7]. These features included the following:

- A lumbosacral curve that defines the back from the buttock.

- Two defined presacral dimples or supragluteal fossettes.

- Two slight lateral depressions overlying the greater trochanters of the femur.

- Short infragluteal creases (not extending laterally beyond the medial half of the posterior thigh).

- A point of maximum projection on the lateral view that corresponds to the level of the mons pubis. The ratio of the anterior superior iliac spine to the greater trochanter and the greater trochanter to the lateral point of maximum projection of the buttock should not exceed 1:2.

Centeno stressed the effects of the aesthetic subunits that surround the gluteal area and their impact on the aesthetics of the gluteal area itself. He mentioned the subunits that must be analysed before the performance of any type of body contouring surgery to the gluteal area to achieve the best results ( 2 symmetrical "flank "units, 1 "sacral triangle" unit, 2 symmetrical gluteal units, 2 symmetrical thigh units, and 1 "infragluteal diamond" unit) [1].
Mendieta [14] demonstrated the aesthetic value of the ratio of the intergluteal fold length and the length of the sacral height (ideally, it is greater than 0.5 but less than the full sacral height). He gave a simple classification for buttock shapes (round, A-shaped, V-shaped, square shaped and intermediate) and gave a simple classification of buttock ptosis. Mendieta also defined five zones that directly surround the buttocks and determine its aesthetics, namely, the sacrum V-zone, flank, upper buttock, lower back, and outer thighs [15].

According to the works of Roberts et al., [16], Heidekrueger et al., [17] and Wong et al., [18], there are significant variations in ideal aesthetic parameters among various human ethnic and racial groups.

The authors of this work adopted their own analytical method and believe that this analytical method is more comprehensive yet simple. The method helps body contouring surgeons in planning for surgical aesthetic procedures on the back of the trunk, thighs and gluteal area.

\section{PATIENTS AND METHODS}

This study took place in the Plastic and Reconstructive Surgery Department in the University Hospital where the authors work and in private practice. The study examined the aesthetic outcomes of the enhancement of the gluteal area by liposuction and fat transfer and compared the results during the following two time periods: Group (A) in the period between 2007 and 2014 (150 female patients), and Group (B) in the period between 2015 and 2018 (100 female patients). All patients underwent liposuction and fat transfer to the subcutaneous tissues of the gluteal area.

All participants were subjected to a full clinical history and general clinical examination to confirm their fitness for surgery i.e., fulfilling the criteria of the American Society of Anaesthesiologists (ASA) grades I \& II. The exclusion criteria included patients with the following conditions: Coagulopathies, uncontrolled hypertension, obligatory antiplatelet and anticoagulant drug administration, unrealistic expectations, younger than the legal age, high Body Mass Index (BMI) (35 or greater), previous liposuction to the trunk area, history of aesthetic enhancement of the gluteal area, buttock ptosis, significant weight loss, musculoskeletal anomalies and poor compliance to the follow-up programme. Any patient who showed overt weight gain or overt weight loss at the time of the final follow-up visit was excluded. 
Informed consent forms were signed by the patients of the two studied groups including statements regarding scientific photography and the potential use of their data and photographs in scientific studies and publications. Photographs of patients from both groups were published using the same views used by Wong et al., 2016 [18] and Heidekrueger et al., 2017 [18].

- Group (A): This group was operated during the time period between 2007 and 2014 before the era of high definition liposuction. The aesthetic assessment and surgical planning according to the criteria suggested by Centeno in 2006 [1]. (See previous content) and liposuction were performed using the traditional method (liposuction of the layer of fat that lies deep to the membranous layer of the superficial fascia). This group data were used retrospectively as a control group.

- Group (B): This group was operated during the time period between 2015 and 2018. The aesthetic assessment and surgical planning according to the criteria suggested by the authors of this work and liposuction were performed according to the new principles of the liposculpture method (superficial liposuction-high definition liposuction) $[19,20]$.

In Group (B), the authors advocated the aesthetic analysis of the following subunits (areas) Figs. $(1,2)$ :

- Areas 1 and 2, i.e. the back: The entire back (not only the lower back).

- Areas 3 and 4, i.e. the flanks.
- Area 5, i.e. the sacral triangle: The inverted triangle with its base superiorly with the line between the overt sacral dimples.

- Areas 6 and 7, i.e. the buttocks: Include a, b, and c, as described below:

"a": Overall fullness and location of the maximum projection point on the lateral view.

"b": The length of the intergluteal cleft.

"c": The infragluteal line.

- Areas 8 and 9, i.e. the trochanteric area.

- Area 10, i.e. the infragluteal diamond.

- Areas 11 and 12, i.e. the lateral thighs.
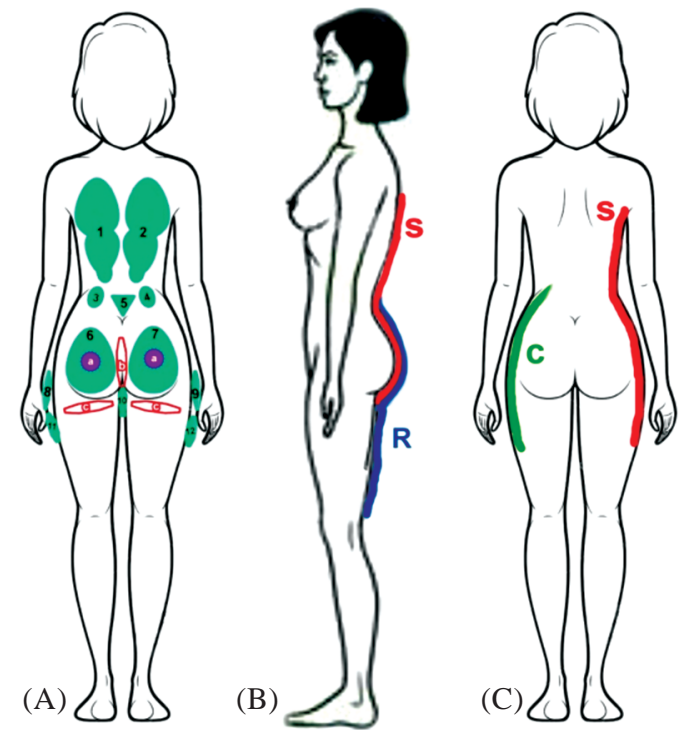

Fig. (1): (A) Buttocks and buttocks-related aesthetic subunits (areas) according to the plan adopted by the authors. (B,C) The aesthetic curves of the female body $(\mathrm{C}, \mathrm{R}$, and $\mathrm{S})$ relations with aesthetic units of the plan adopted by the authors.

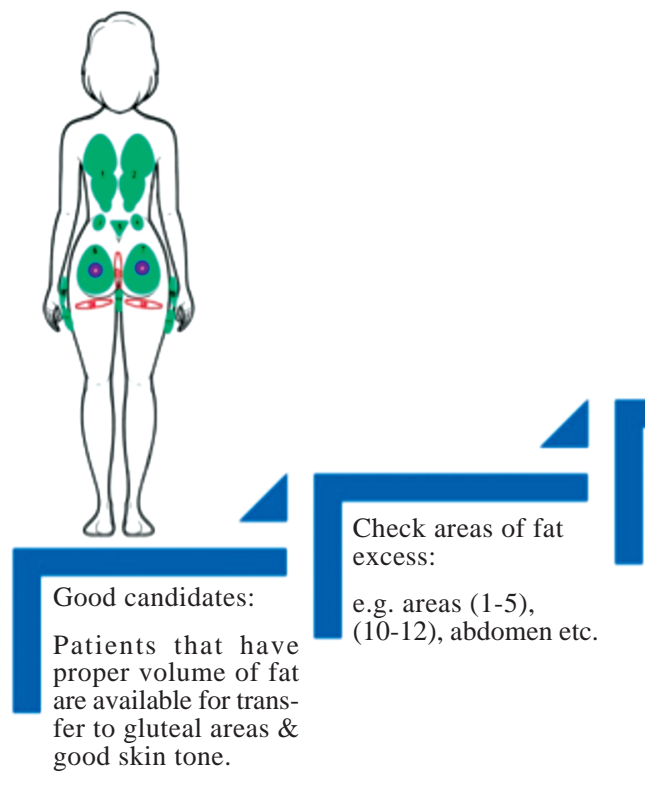

Define which gluteal related areas that need filling:

Decide according to patients race, body characters and/or personal demands

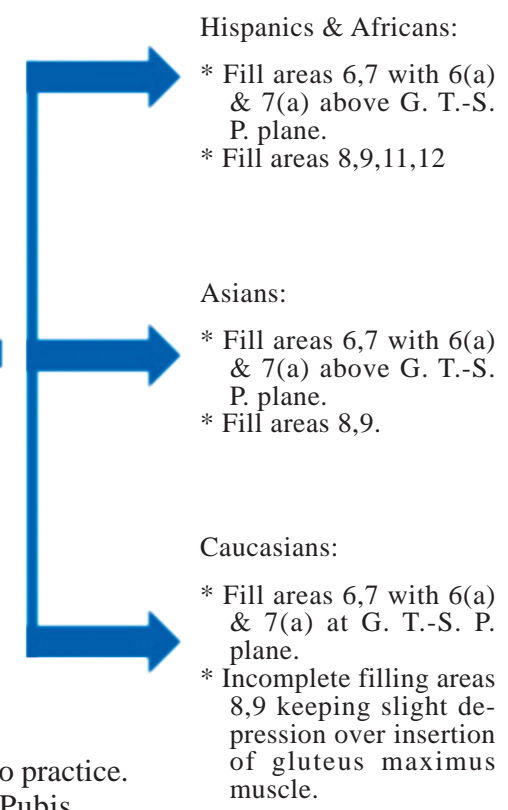

Fig. (2): Example of the authors adopted plan put into practice *G.T. $=$ Greater Trochanter. $\quad *$ S.P. $=$ Symphysis Pubis. 


\section{Operative steps:}

Infiltration of the selected areas for liposuction in patients of both groups was performed according to the Klien formula [21].

- Group (A) patients: Liposuction of the deep fat (deep to the membranous layer of the superficial fascia).

- Group (B) patients: Liposuction of the deep and superficial fat (in relation to the membranous superficial fascia) according to the criteria of high-definition liposuction, i.e. liposuction of both deep and superficial fat accumulations in the back with care to create a smooth and gradual transition area between the buttocks and flanks and eliminate any back rolls [3].

In both groups: Liposuction was performed using a $3-\mathrm{mm}$ accelerator cannula. Fat tissue was left in the containers to be decanted. Fat tissue was loaded into $20-\mathrm{ml}$ syringes for transfer. The fat tissue was injected into the subcutaneous tissue of the buttocks taking extreme care to avoid intramuscular injection. The authors used 4-mm gauge fat transfer cannulas of variable lengths (from Delta Med SurgicalR, Sialkot, Pakistan). The fat tissue was transferred to the buttocks according to the assessment (each group according to its assigned assessment method).

- In Group (A), the fat tissue was transferred and distributed to increase the volume of the gluteal unit described by Centeno [1].

- In Group (B), the fat tissue was transferred according to the authors' assessment criteria, i.e. in a differential manner to achieve maximum results in the gluteal unit and its subunits $(a, b$ and c) as well as the trochanteric and thigh units according to the patient's demands or ethnic background. The lateral thigh units were managed by liposuction or fat transfer according to each patient's ethnic background and demands Fig. (2).

The liposuction ports were closed with $5 / 0$ Vicryl RapideR in both groups; however, in Group (B), the dependent liposuction ports were left (without stitches) to establish free drainage.

A pressure garment was used by all patients for three months after surgery.

Photographic documentation was acquired preoperatively and at the end of the first six postoperative months (posterior and lateral views). The photography session during the last follow-up visit was considered to be the post-operative photograph- ic result as long as it was performed six months or more after surgery.

Subjective assessment of the results for all patients after at least six months according to the following scale.

3 points: Excellent results.

2 points: Fair results.

1 point: Poor results.

The pre and post-operative photography (at least six months post-operative pictures) were assessed by independent observers (four plastic surgeons from other university) for objective opinion depending on the degree of asymmetry, persistence of deformities and/or irregularities in the results using the same scale. The collected data of the degrees of satisfaction of both patient and objective opinion were used to measure patient/ objective assessment agreement by Kappa statistical analysis (no agreement $K=0$, slight agreement $K=$ less than 0.2 , fair agreement $K=0.21$ to 0.4 , moderate agreement $\mathrm{K}=0.4$ to 0.6 , substantial agreement $\mathrm{K}=0.6$ to 0.8 and perfect agreement $\mathrm{K}=0.8$ to 1 ) [22].

\section{RESULTS}

A total of 250 female patients participated in this study and were arranged into two groups Figs. (3-14):

- Group (A): 150 patients (during the period between 2007 and 2014).

- Group (B): 100 patients (during the period between 2015 and 2018).

The Kappa statistical analysis [22] showed that the agreement between patients' opinion and objective assessment was substantial as regard to results $(\mathrm{K}=0.751)$ of Group (A) and was perfect regarding to Group (B) (0.831).

\section{DISCUSSION}

The curvatures of the female back and buttocks were described by Aristotle as the most attractive form in the human body [23]. Like the abdomen to the front of the trunk, due to the central location of the gluteal area, it affects and is affected by the surrounding aesthetic subunits. It is logical to state that the entire back of the trunk, buttocks, and thighs are aesthetically interactive [1]; thus, there are cases in practice that result in a very nice aesthetic enhancement of the buttocks by liposuction of the surrounding subunits without any fat transfer Fig. (15) (a demonstrative case that was excluded from this study). 


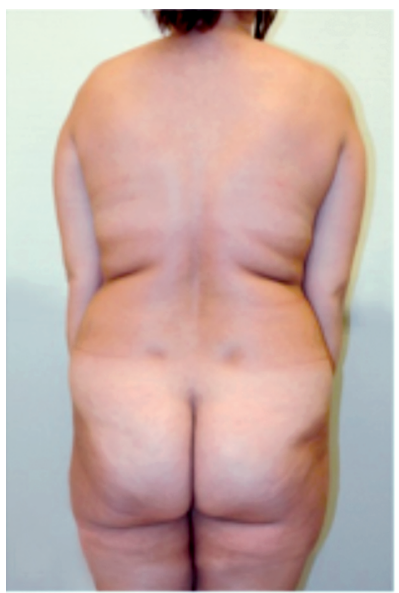

(A)

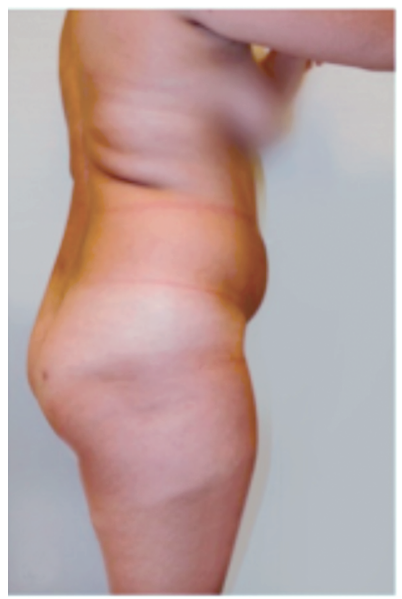

(B)

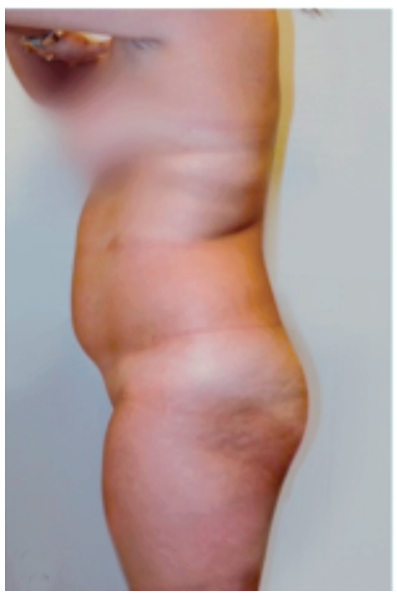

(C)

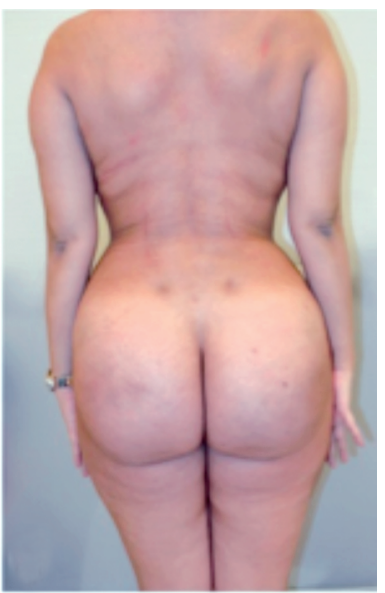

(D)

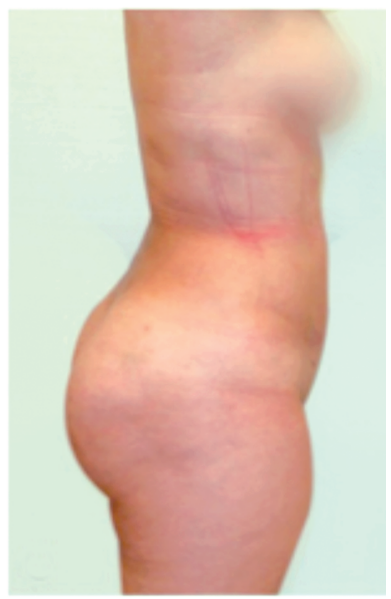

(E)

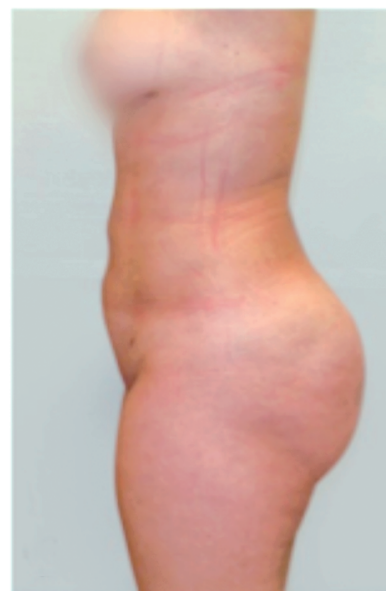

(F)

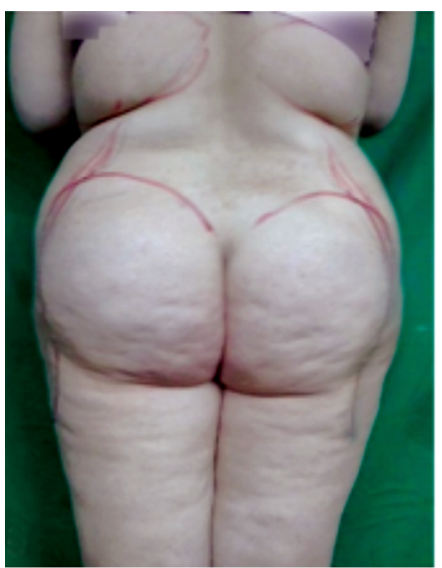

(A)

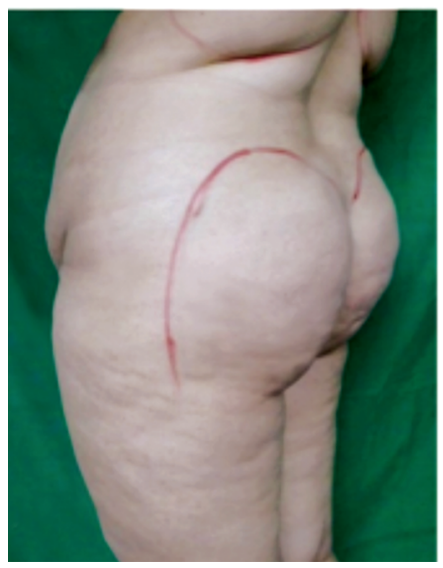

(B)

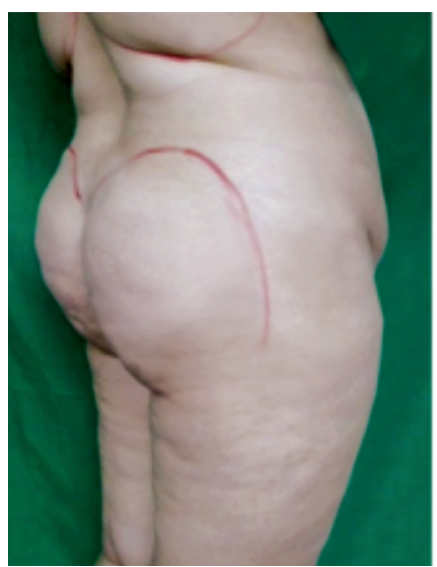

(C)

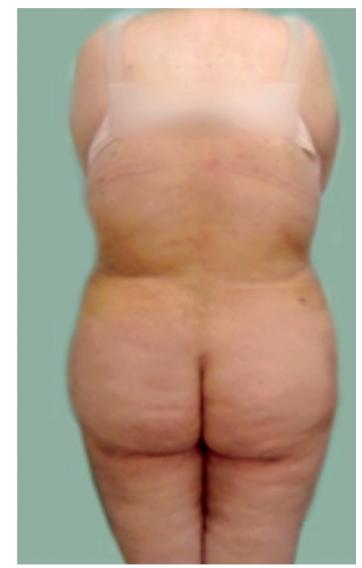

(D)

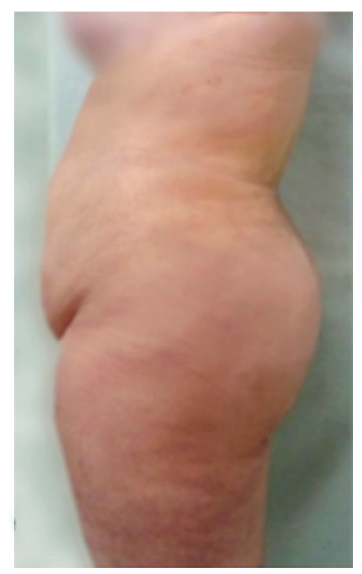

(E)

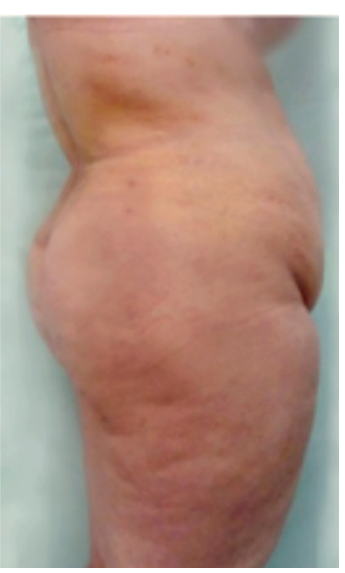

(F)

Fig. (3): Group (A) patient, aged 27 years, with a good outcome. (A, B, C) Pre-operative views. (E, F, G) Post-operative views after liposuction of 5 liters of fat from the abdomen, back, and flanks. Fat was transferred to buttocks (1050ml per buttock).

Fig. (4): Group (A) patient, aged 34 years, with a good outcome. (A, B, C) Pre-operative views. (D, E, F) Post-operative views after liposuction of 6 liters of fat from the abdomen, back, and flanks. Fat was transferred to buttocks ( $1250 \mathrm{ml}$ per buttock). 


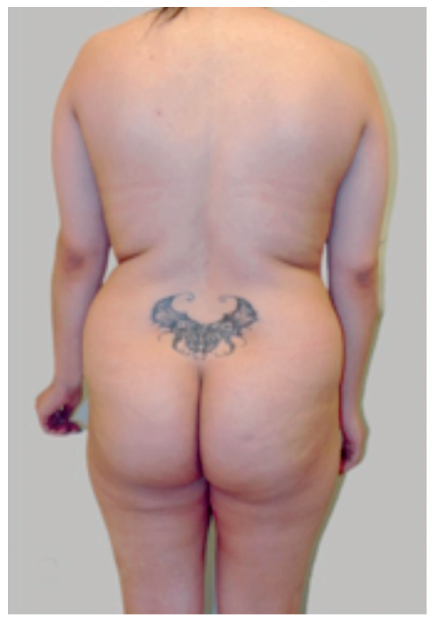

(A)

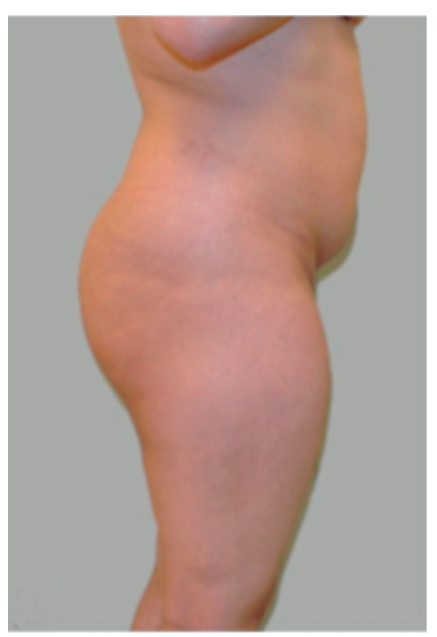

(B)

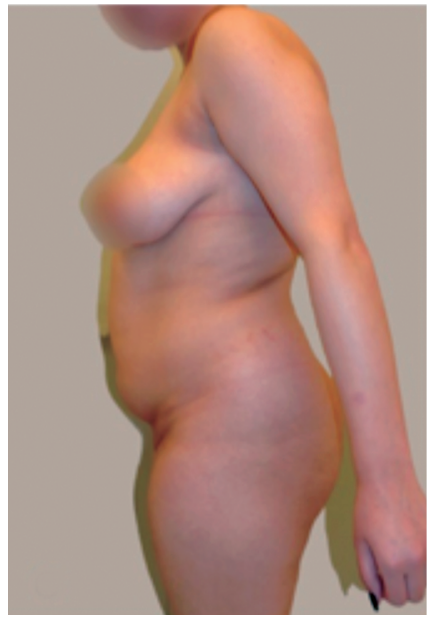

(C)

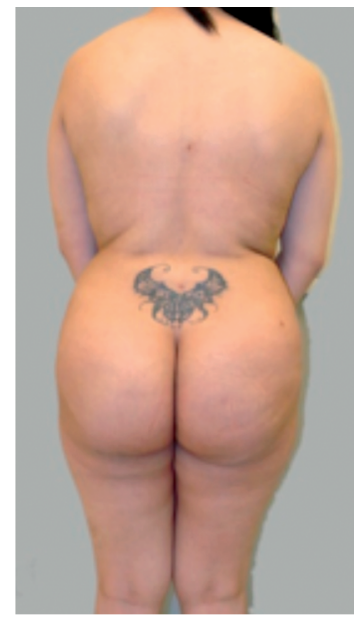

(D)

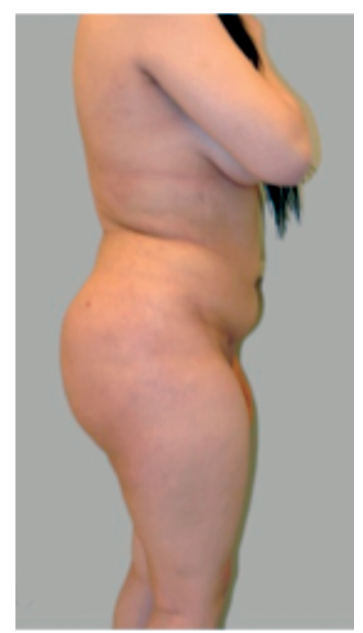

(E)
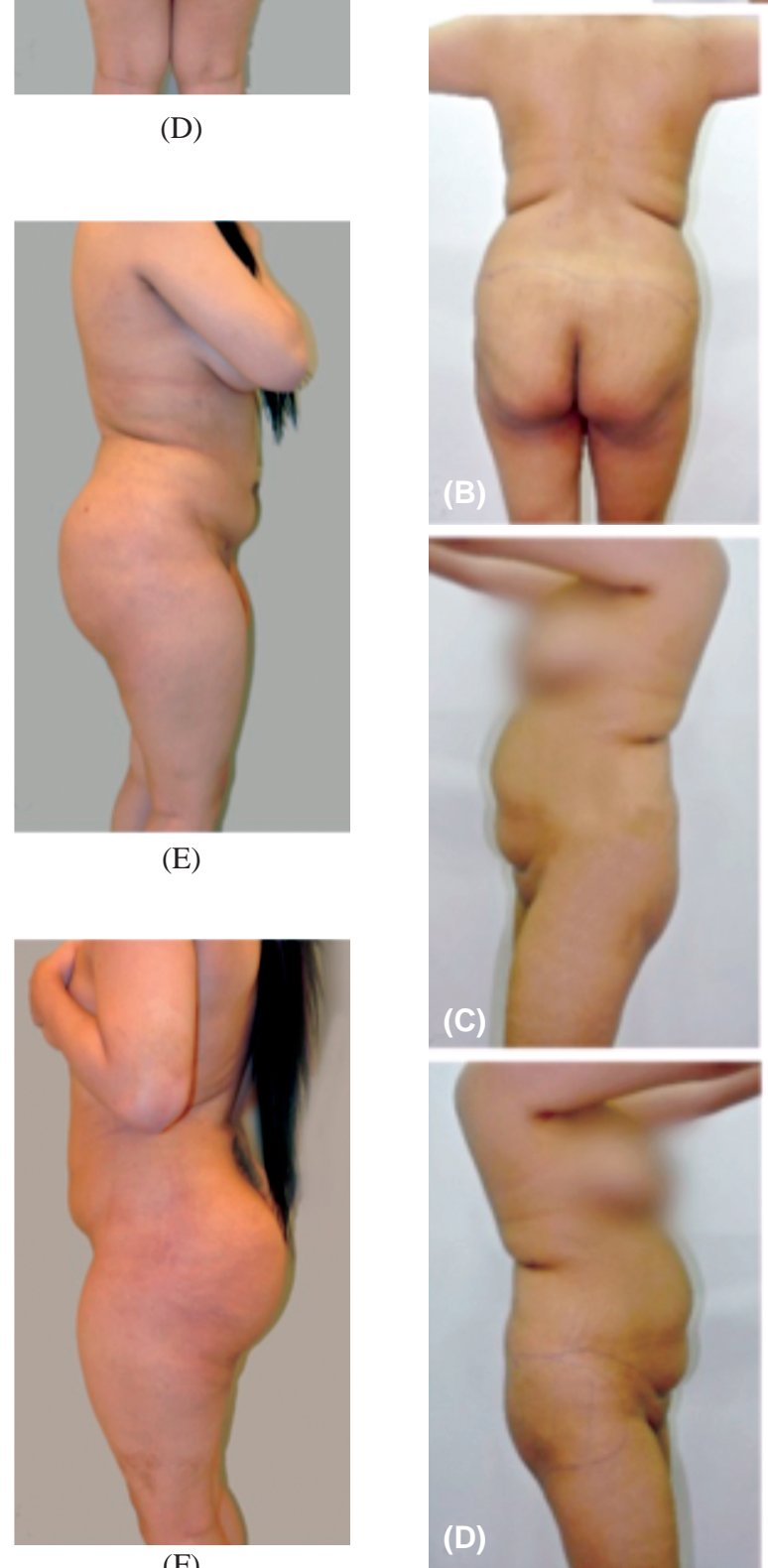
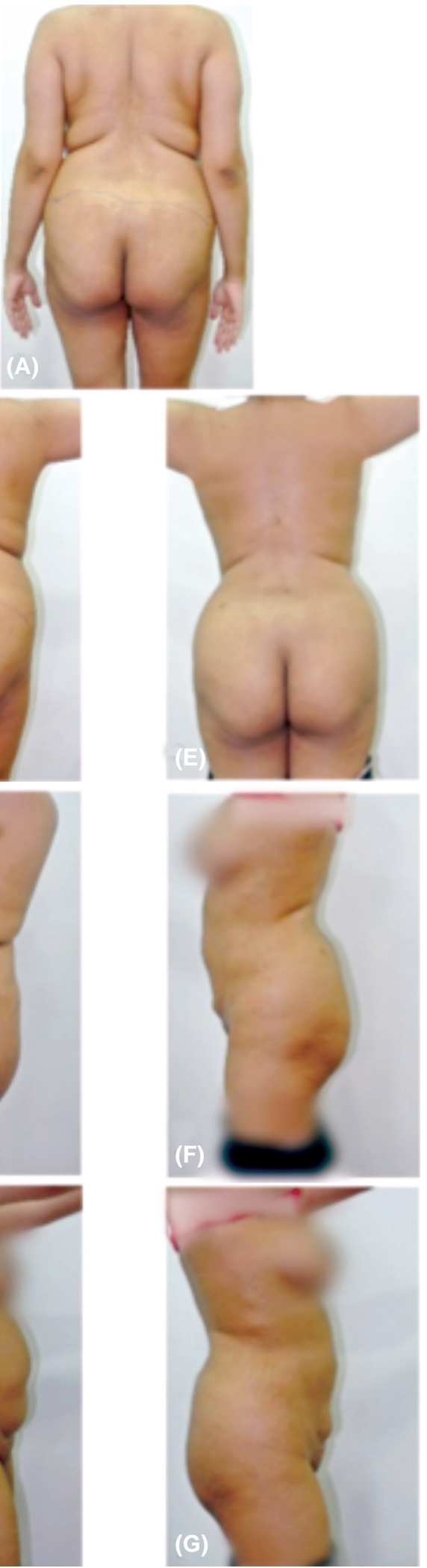

(F)
Fig. (5): Group (A) patient, aged 23 years, with residual back rolls. (A, B, C) Pre-operative views. (D, E, F) Postoperative views after liposuction of 4 liters of fat from the abdomen, back, and flanks. Fat was transferred to buttocks ( $900 \mathrm{ml}$ per buttock).
Fig. (6): Group (A) patient, aged 29 years, with residual back rolls, residual fullness and modest improvement in the posterior projection of the buttocks. (A, B, C) Preoperative views. (D, E, F) Post-operative views after liposuction of 4.8 liters of fat from the abdomen, back, and flanks. Fat was transferred to buttocks (1300ml per buttock). 

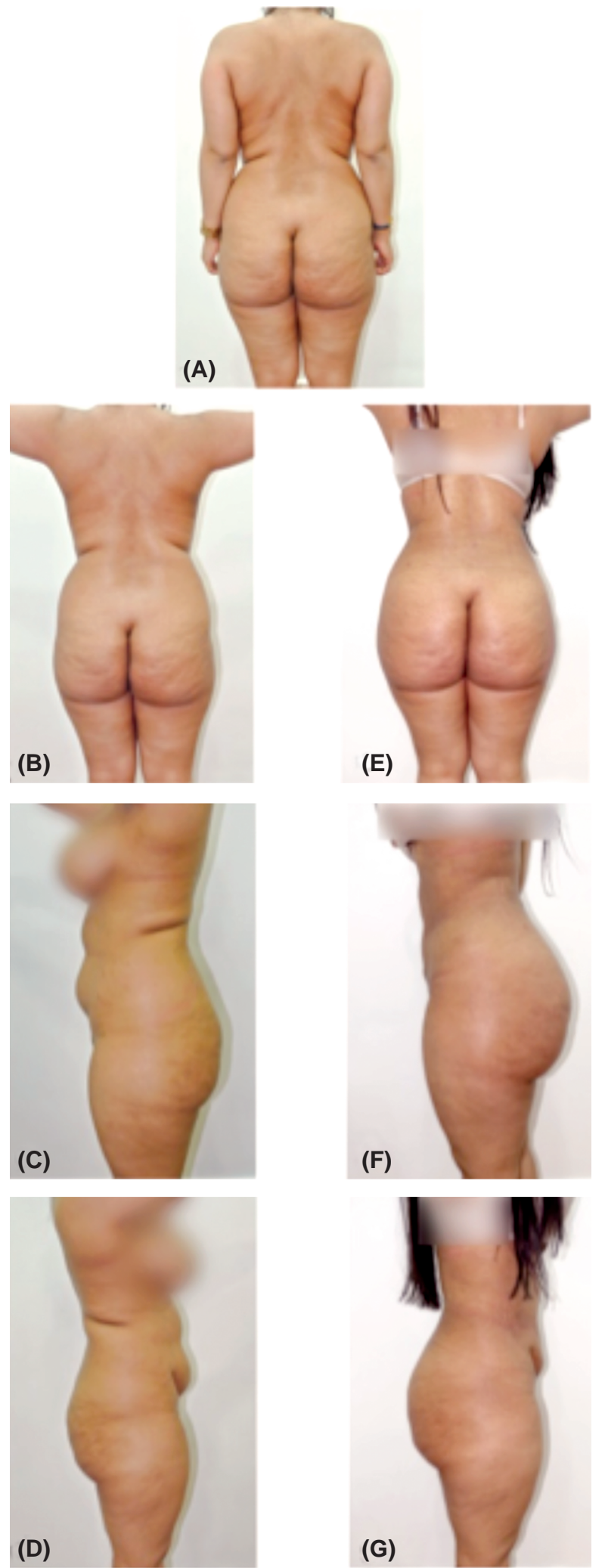

Fig. (7): Group (B) patient, aged 26 years, from a Hispanic ethnic background (from Puerto Rico). (A, B, C, D) Preoperative views showing fullness in areas $(1,2,3,4,5)$ and emptiness in areas $(6,7,8,9)$. (E, F, G) Post-operative views after liposuction of 3.6 liters of fat from the abdomen and areas $(1,2,3,4,5)$ and $900 \mathrm{ml}$ of fat transfer to areas $(6,7$, $8,9)$. The patient did not want a diamond zone (area 10).
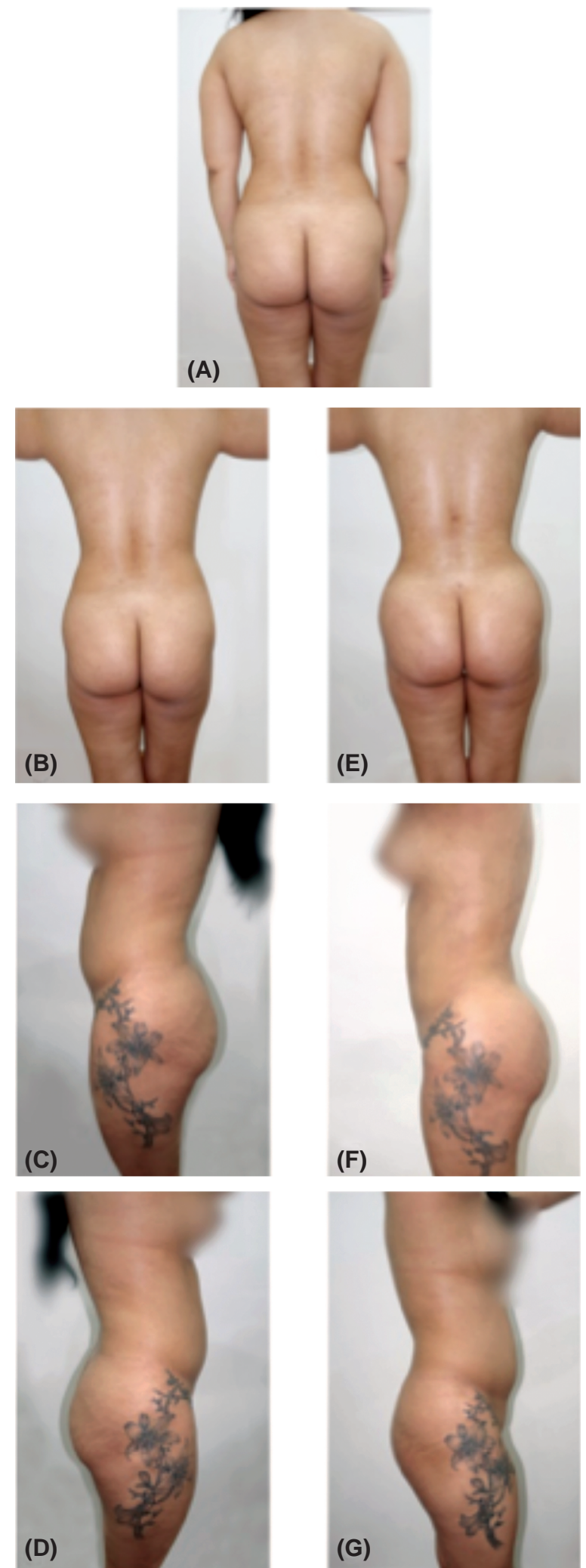

Fig. (8): Group (B) patient, aged 30 years, from an Arabian Gulf ethnic background. (A, B, C, D) Pre-operative views showing fullness in areas $(1,2,3,4,5)$ and emptiness in areas $(6,7,8,9)$. (E, F, G) Post-operative views after liposuction of 3.6 litres of fat from the abdomen and areas $(3,4,5)$ and $750 \mathrm{ml}$ of fat transfer to areas $(6,7,8,9)$. The patient did not want a diamond zone (area 10). Fullness in the upper part of area (9) was preferred by the patient to give what she called a heart-shaped buttock. 


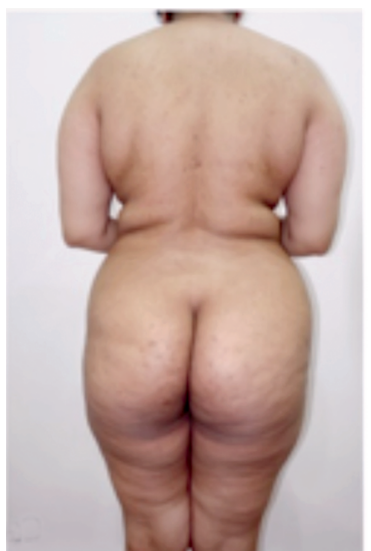

(A)

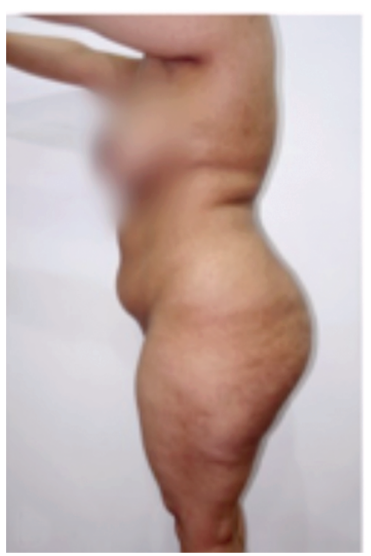

(B)

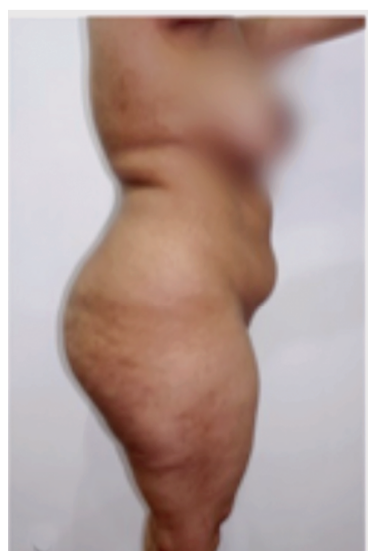

(C)

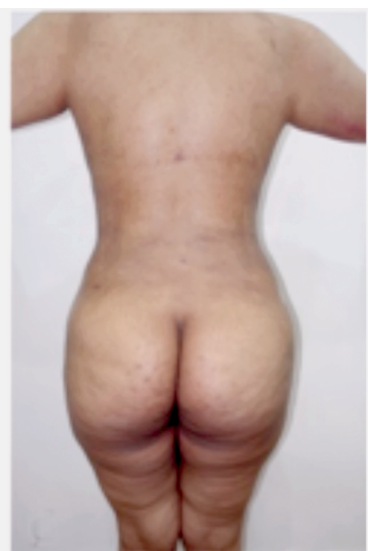

(D)

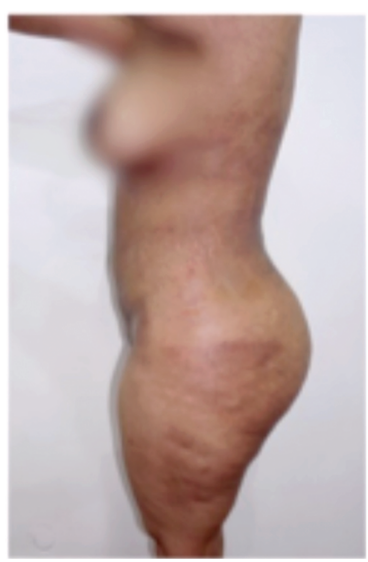

(E)

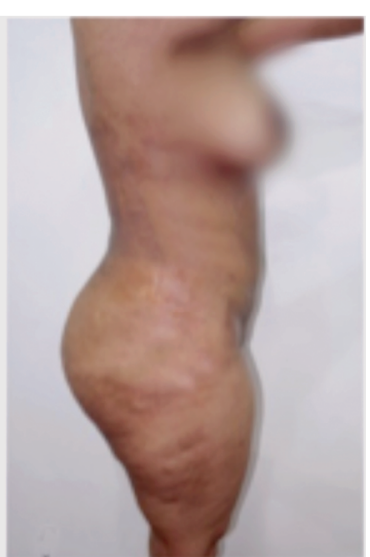

(F)
Fig. (9): Group (B) patient, aged 36 years, from an African ethnic background (North Sudan). (A, B, C) Pre-operative views are showing fullness in areas $(1,2,3,4,5)$ and emptiness in areas $(8,9)$. The patient asked to add more posterior projection to areas $(6,7)$. (D, E, F) Post-operative views after liposuction of 5.2 liters of fat from the abdomen and areas $(1,2,3,4,5)$ and $800 \mathrm{ml}$ of fat transfer to areas $(6,7,8,9$. The patient did not want to have a diamond zone (area 10), and she was satisfied regarding the shape of areas 11 and 12 .

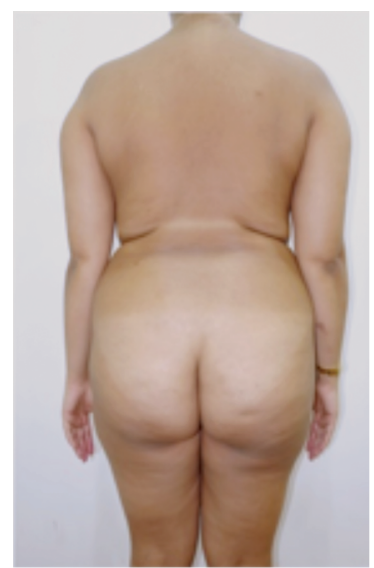

(A)

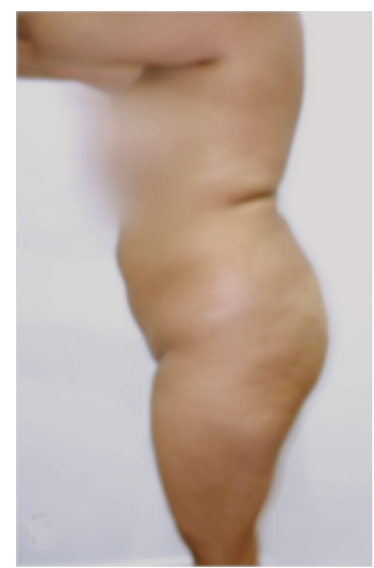

(B)

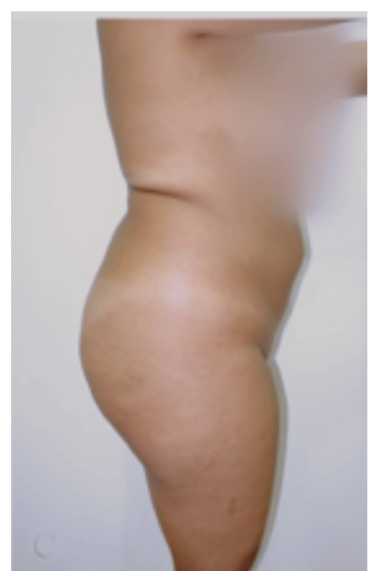

(C)

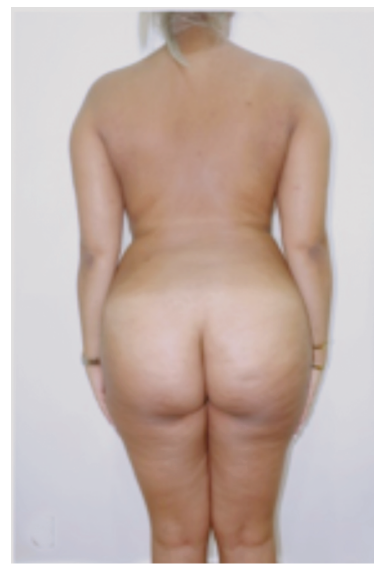

(D)

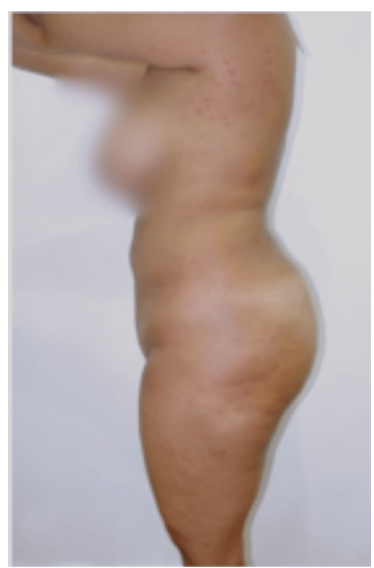

(E)

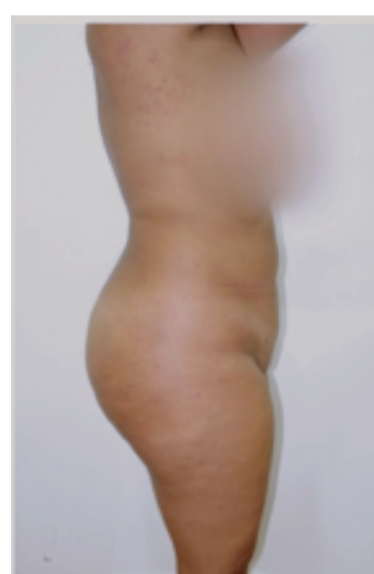

(F)
Fig. (10): Group (B) patient, aged 32 years, from a North African ethnic background (from Morocco). (A, B, C, D) Preoperative views are showing fullness in areas $(1,2,3,4,5)$ and shortness in areas $(6 \mathrm{~b}, 7 \mathrm{~b})$. The patient asked for more posterior projection areas $(6,7)$ and a slight reduction in the lateral thighs areas $(11,12)$. (E, F, G) Post-operative views after liposuction of 3.8 liters of fat from the abdomen and areas $(1,2,3,4,5,11,12)$ and 1 liters of fat transfer to areas $(6,7,8,9)$. The patient did not want to have a diamond zone (area 10). 

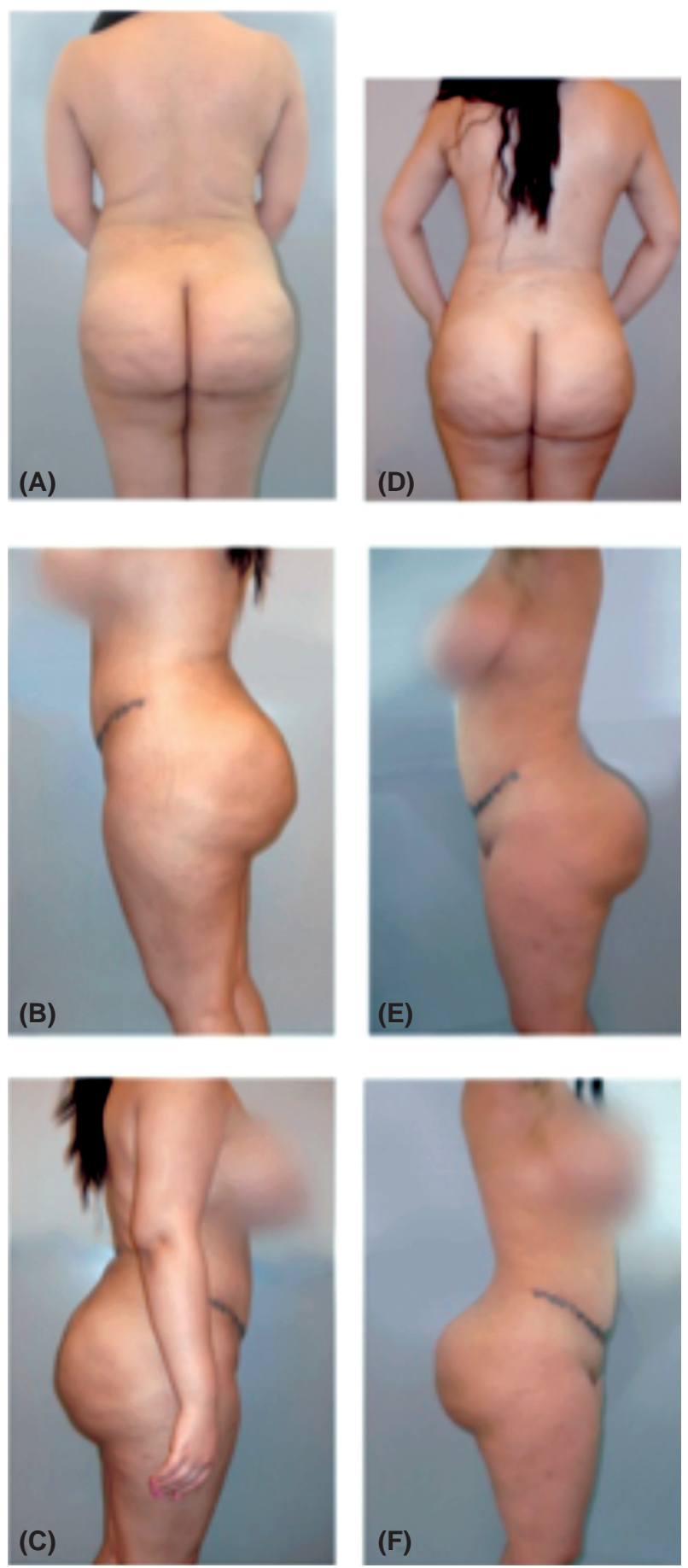

Fig. (11): Group (B) patient, aged 35 years, from a European Mediterranean ethnic background (from Italy). (A, B, C) Pre-operative views showing fullness in areas (1, 2, 3, 4, 5 ) and asymmetry between areas $(8,9)$; The patient asked for Hispanic-shaped buttocks and waist (she used the media nickname Spanish waist). (D, E, F) Post-operative views after liposuction of 3.8 liters of fat from the abdomen and areas $(1,2,3,4,5)$ and $900 \mathrm{ml}$ of fat transfer to areas $(6,7,8,9)$. The maximum posterior projection point areas $(6 \mathrm{c}, 7 \mathrm{c})$ were adjusted above the level of the symphysis pubis-greater trochanter plane. The patient did not want to have a diamond zone (area 10).
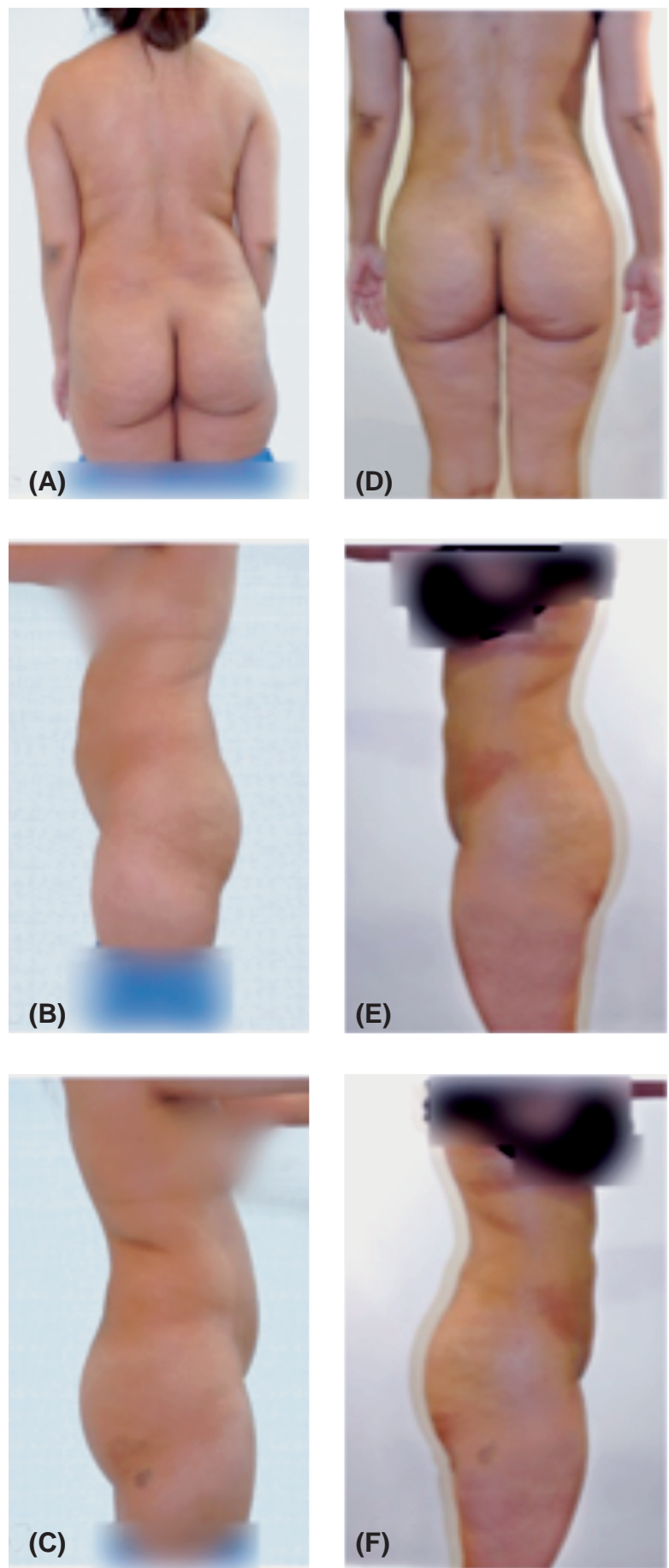

Fig. (12): Group (B) patient, aged 28 years, from an East European ethnic background (from Bosnia). (A, B, C) Preoperative views showing asymmetry between areas $(11,12)$, and fullness in areas $(1,2,3,4,5)$. The patient asked for a narrow waist and fuller buttocks with a mild posterior projection and a diamond zone (area 10). (D, E, F) Post-operative views after liposuction of 2.4 liters of fat from the abdomen and areas $(1,2,3,4,5,10,11,12)$ and $700 \mathrm{ml}$ of fat transfer to areas $(6,7,8,9)$. 


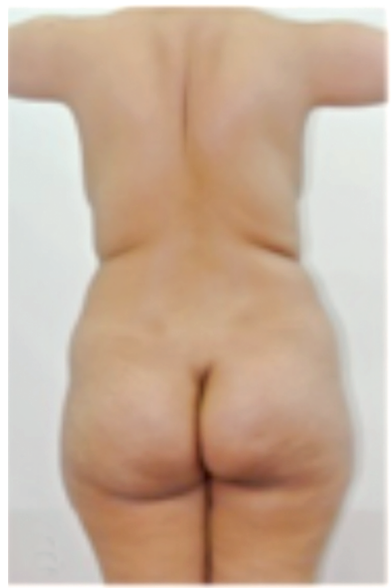

(A)

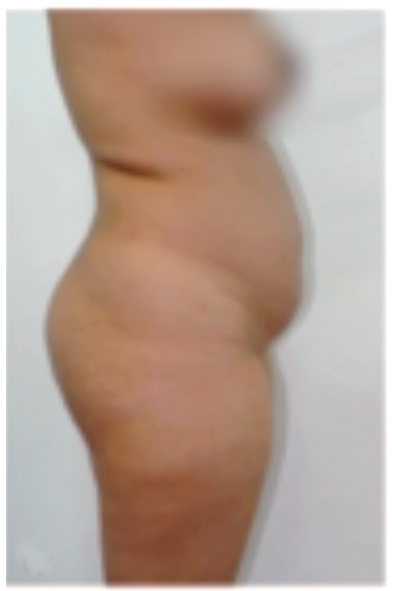

(B)

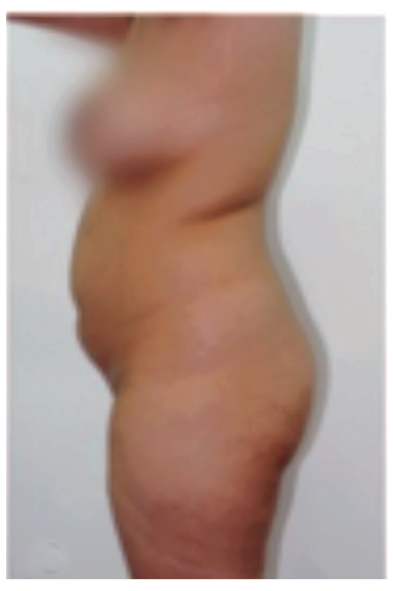

(C)

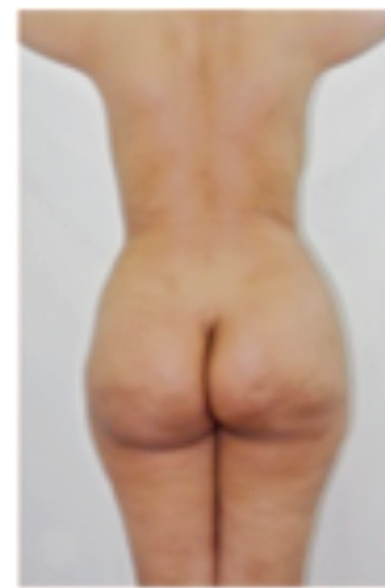

(D)

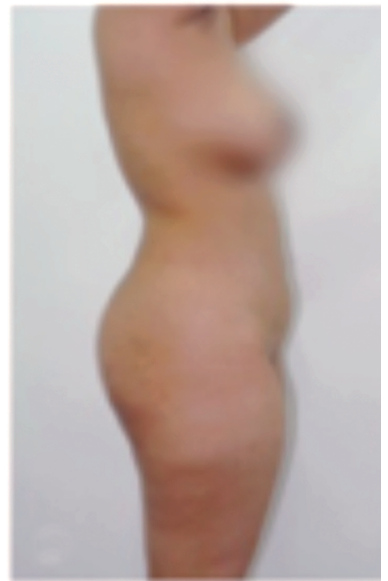

(E)

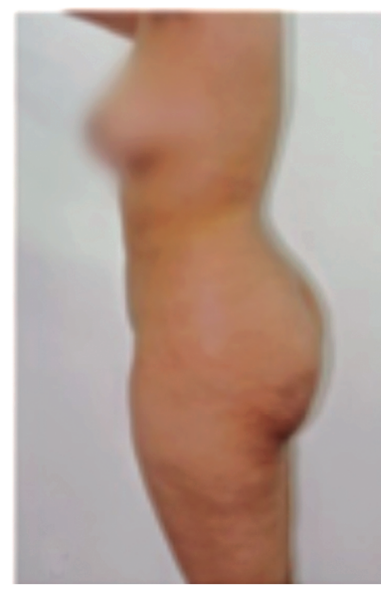

$(\mathrm{F})$
Fig. (13): Group (B) patient, aged 36 years, from a European/Asian ethnic background (from Turkey). (A, B, C) Preoperative views showing fullness in areas $(1,2,3,4,5)$, emptiness in areas $(7,8)$ and asymmetry in the intergluteal cleft $(6 \mathrm{~b}, 7 \mathrm{~b})$. The patient asked for rounded buttocks with an enhanced posterior projection. (D, E, F) Post-operative views after liposuction of 4.4 liters of fat from the abdomen and areas $(1,2,3,4,5,10,11,12)$ and $1 \mathrm{~L}$ of fat transfer to areas $(6,7,8,9)$. The patient did not want to have a diamond zone (area 10). There was persistence of her intergluteal cleft asymmetry after surgery. She is the only patient in this series with intergluteal cleft asymmetry.
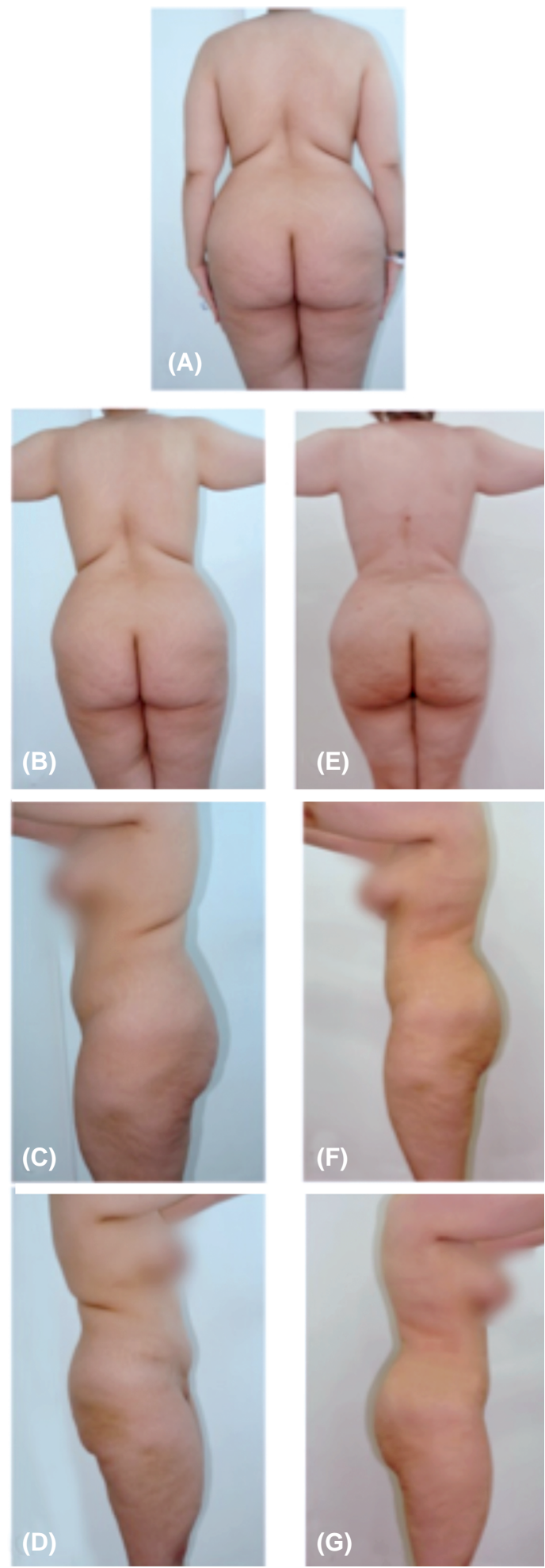

Fig. (14): Group (B) patient, aged 34 years, from a West Asian ethnic background (from Iran) with residual fullness in the flanks and back rolls (areas 1, 2, 3, 4). (A, B, C, D) Pre-operative views showing fullness in areas $(1,2,3,4,5)$ and emptiness in areas $(6,7)$. The patient asked for rounded buttocks with posterior projection. (E, F, G) Post-operative views after liposuction of 4.7 liters of fat from the abdomen and areas $(1,2,3,4,5)$ and $1.2 \mathrm{~L}$ of fat transfer to areas $(6$, $7,8,9)$. The patient did not want to have a diamond zone (area 10). 

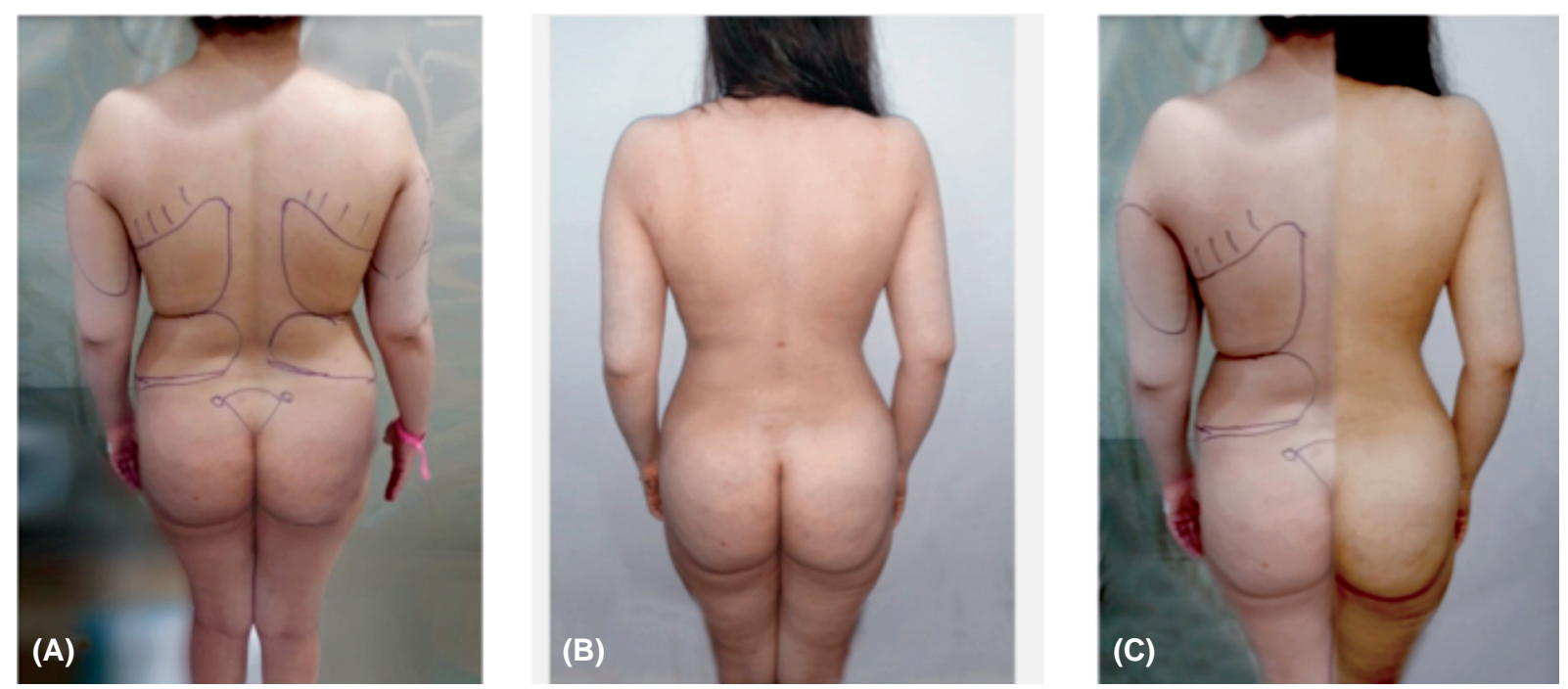

Fig. (15): Overt improvement in the shape of the buttocks using liposuction and only following the authors' adopted algorithm (this case was excluded from the study as no fat transfer was performed). (A) Pre-operative posteroanterior view. (B) Postoperative posteroanterior view. (C) Constructed comparative posteroanterior view.
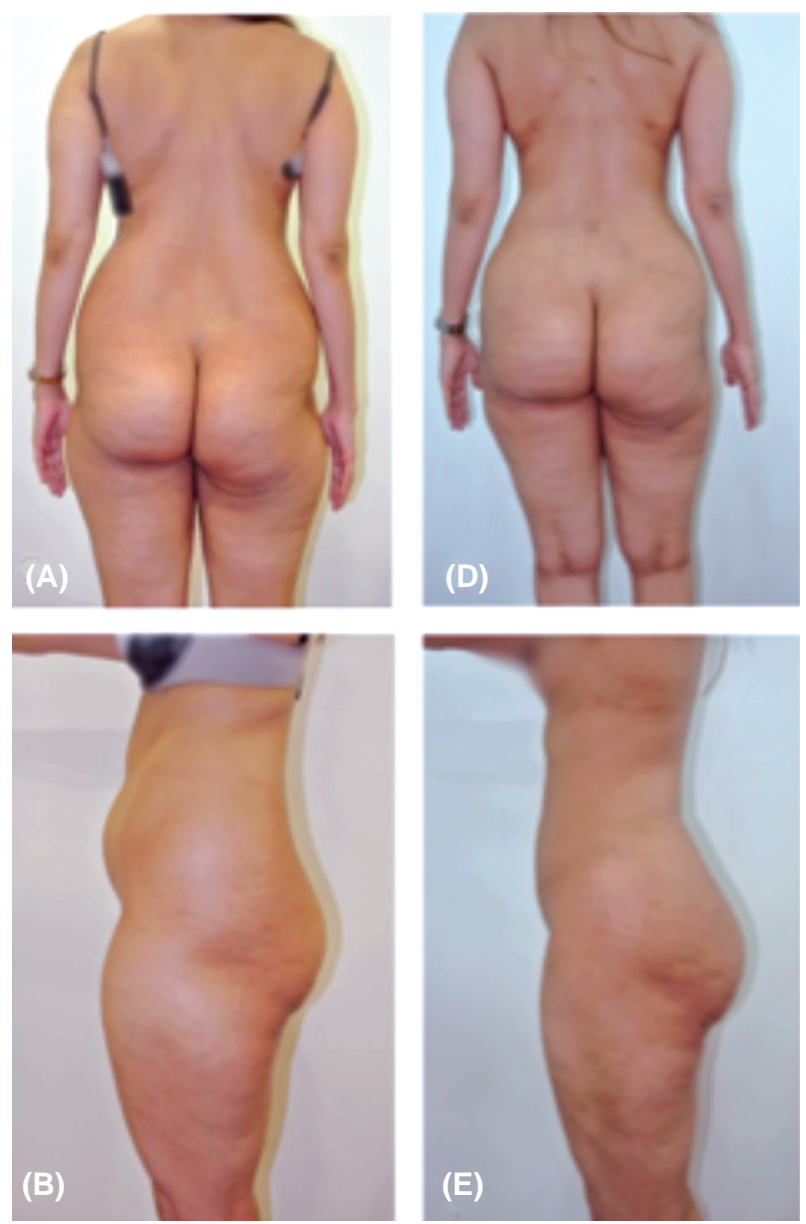

Table (1): Liposuction volume in litres.

\begin{tabular}{lcccc}
\hline Group & Minimum & Maximum & Average & Mean \\
\hline A & 1.2 & 3.7 & 2.45 & 2.9 \\
B & 2.3 & 4.30 .002 & 3.3 & 3.8 \\
$p$-value & & & & \\
\hline
\end{tabular}
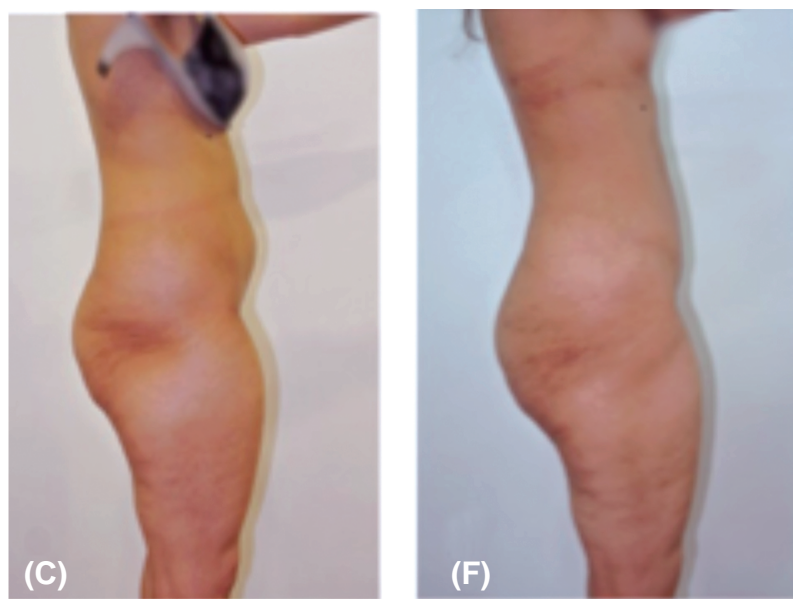

Fig. (16): A patient from a North African ethnic background (from Libya) gave a history of poliomyelitis affecting the right gluteus maximus. (A, B, C) Pre-operative views. (D, E, F) Post-operative views after liposuction of 3.2 litres of fat from the abdomen and areas $(1,2,3,4,5)$. Fat was transferred to areas $(7,9)$ to increase the size of the right buttock in all dimensions and to minimize asymmetry $(600 \mathrm{ml}$ fat). The patient showed partial improvement in her asymmetry, and she is scheduled for another session of fat transfer. This patient was excluded from the study due to the severe musculoskeletal pathology.

Table (2): Total volume of transferred fat tissue for both buttocks.

\begin{tabular}{lcccc}
\hline Group & Minimum & Maximum & Average & Mean \\
\hline A & 1.8 & 2.6 & 2.2 & 1.9 \\
B & 1.2 & 2.4 & 1.8 & 1.3 \\
$p$-value & & 0.009 & & \\
\hline
\end{tabular}


Table (3): Complications of the fat tissue transfer procedures.

\begin{tabular}{lcl}
\hline Group & Seroma & \multicolumn{1}{c}{$\begin{array}{c}\text { Liposuction port } \\
\text { complications }\end{array}$} \\
\hline A (150 patients) & $6 \%$ (9 patients) & $15.33 \%$ (23 patients) \\
B (100 patients) & $3 \%$ (3 patients) & $4 \%$ (4 patients) \\
\hline
\end{tabular}

Table (4): Patient satisfaction data.

\begin{tabular}{llll}
\hline Group & Excellent & Fair & Poor \\
\hline A & $74 \%$ & $14 \%$ & $12 \%$ \\
(150 patients) & $(111$ patients $)$ & $(21$ patients $)$ & $(18$ patients $)$ \\
B & $88 \%$ & $8 \%$ & $4 \%$ \\
(100 patients) & $(88$ patients $)$ & $(8$ patients $)$ & $(4$ patients $)$ \\
\hline
\end{tabular}

Table (5): Main causes of dissatisfaction.

\begin{tabular}{lcclc}
\hline $\begin{array}{l}\text { Dissatisfied } \\
\text { patients }\end{array}$ & $\begin{array}{c}* \text { Not satisfied } \\
\text { with buttock } \\
\text { shape }\end{array}$ & $\begin{array}{c}\text { *Buttocks } \\
\text { smaller } \\
\text { than expected }\end{array}$ & *Complication & $\begin{array}{c}\text { Residual } \\
\text { back } \\
\text { rolls }\end{array}$ \\
\hline $\begin{array}{l}\text { Group (A) } \\
18(12 \%)\end{array}$ & 3 & 5 & $\begin{array}{l}\text { 1. Seroma (2) } \\
\text { 2. Liposuction port complications (2) }\end{array}$ & 6 patients \\
$\begin{array}{l}\text { Group (B) } \\
4(4 \%)\end{array}$ & & 2 & Seroma (1) & 1 patient \\
\hline
\end{tabular}

This work aimed to produce a comprehensive yet simple analytical tool to assist body contouring surgeons in planning for surgical aesthetic procedures of the back, thighs, and gluteal area.

The authors advocated for these subunits (better known as areas where the junctions between them are ill-defined and smooth shifts Fig. (1):

- Areas 1 and 2, i.e., the back: The entire back (not only the lower back) is an integral part that was not evaluated in the previous works of other authors. The back with no rolls helps show the beauty of the "S" curve of the buttocks in the posterior and lateral views, as described by Hoyos [24].

- Areas 3 and 4, i.e., the flanks: The empty flanks enhance the appearance of sizable buttocks and vice versa. Additionally, the smooth shift between the buttocks and flanks enhances the " $S$ " curve of the buttocks and flanks [24] in the posterior view. This aesthetic " $\mathrm{S}$ " curve is valued by several human cultures, even in ancient history $[2,23]$.

- Area 5, i.e., the sacral triangle: The inverted triangle with its base superiorly located at the level of the line between the overt sacral dimples and the apex inferiorly located at the sacrococcygeal junction level.

- Areas 6 and 7, i.e., the buttocks: These areas include the following:

"a": Overall fullness and location and projection of the maximum projection point in the lateral view as this element is subjected to racial and subjective variability.

"b": The length of the intergluteal cleft compared to the sacral height (more than half of the buttock's height but less the full sacral height).
The two buttocks share in the creation of this cleft; thus, areas $6 \mathrm{~b}$ and $7 \mathrm{~b}$ are necessary when the intergluteal cleft is described. An asymmetrical intergluteal cleft was present only once in this series Fig. (13). An intergluteal cleft that is too short will give the optical sense of small buttocks, while an intergluteal cleft that is too long will give the buttocks the appearance of so called "alien buttocks" [14]. We did not see an intergluteal cleft that was too long in this series, and it was noted that short clefts were corrected by fat transfer to the upper part of areas 6a and 7a. Liposuction of the flanks gives an optical illusion of reduced sacral height and thus helps to correct the relative shortness of the intergluteal cleft Fig. (10).

"c": The infragluteal line should not cross the meridian of the posterior thigh in aesthetically perfect buttocks. This line crosses the posterior thigh meridian in ptotic buttocks. Patients showing ptotic buttocks were excluded from this study. The well-defined infragluteal line with the absence of a banana fold in the uppermost posterior thigh gives the aesthetic " $R$ " curve when viewing the female form from the lateral and posterior-lateral (oblique) views [24].

- Areas 8 and 9, i.e., the trochanteric area: The fullness and depression in this area are aesthetically subjected to great variation according to cultural, racial and subjective factors and will be detailed later. A full trochanteric area will enhance the "C" curve in the posterior view of the female form [24].

- Area 10, i.e., the infragluteal diamond (diamond zone): It denotes the absence of thigh obesity and partially shows the vulva if viewed from behind. It was noted from our series that patients with slim thighs and a more athletic form usually 
ask for an infragluteal diamond (it was sculptured by liposuction of the medial thigh and lower medial parts of the buttocks) while those with plump curvy forms with robust thighs do not ask for it or even sometimes refuse to have it.

- Areas 11 and 12, i.e. the lateral thighs: The upper lateral thigh shares in the formation of the " $\mathrm{C}$ " curve with the trochanteric area [24]. The lateral thigh is another area that is aesthetically subjected to great variation according to cultural, racial and subjective factors. The restoration of the back/flanks related "C", "S", and "R" curves by liposuction alone can be enough to enhance the gluteal area in some cases (Fig. 15).

According to the works of Roberts et al., [16], Heidekrueger et al., [17] and Wong et al., [18], there are great variations in the ideal aesthetic parameters among ethnic groups. Caucasian Americans prefer more athletic buttocks with greater definition of the muscular and bony anatomy, less posterior projection if compared to other ethnic groups and with maximum projection at the plane connecting the symphysis pubis and greater trochanter (the distance of this point to the greater trochanter is nearly double the distance between the symphysis pubis and the greater trochanter in the lateral view). They favour lateral thigh depression and do not like fullness of the lateral thigh. The Asian American culture favours short buttocks with a higher point of maximum projection (higher than the symphysis pubis-greater trochanter plane), giving the illusion of longer lower limbs and thus, giving better proportion between the trunk and extremities. Hispanic and African American cultures value buttocks having more projection than either Asian or Caucasian Americans. A higher point of maximum posterior projection (higher than the symphysis pubis-greater trochanter plane), deeper lumbosacral curve, and fullness rather than lateral thigh depressions also appear to be favoured by African Americans.

Wong et al., [18] studied ideal parameters of the buttocks in the mass population irrespective of ethnic groups but with consideration of age and sex. They found greater variability in the ideal waist-hip ratio. There were a good percentage of advocates for the ratio values of $0.65,0.7$ and even 0.5 . They found no effect on the woman's overall body size as long as she had an ideal ratio. In the opinion of the authors, the advocated new analytical method accommodates these different racial preferences better than the previous methods. There are even more detailed studies on the vast variety of ideal aesthetic parameters in more selective racial and ethnic subgroups $[25,26]$.
Mendieta and Centeno agreed on nearly the same five aesthetic zones that surround the buttocks, but using a different nomenclature. Mendieta agreed with Centeno and mentioned the work of Centeno in detail in a recent publication [27]. In our opinion, the classifications of Mendieta and Centeno are very similar to one other. In both authors' works, the buttock itself was considered as a single aesthetic area and was not subdivided. The division of the buttock units is important in our opinion. The racial differences in the shape of the buttocks depends on the location of the point of maximum lateral projection (points $7 \mathrm{a}$ and $8 \mathrm{a}$ in the new classification) as well as the trochanteric area and lateral thighs (areas 8, 9, 11 and 12 in the new classification). The importance of the upper back was not emphasized in both the Mendieta and Centeno classifications. The entire back is very important in our opinion, as it forms the curves that define the feminine beauty in the eyes of the beholder. The beholder sees an overall image of the back, thighs and buttocks and not only a focused image of the buttocks and its close surroundings. As previously mentioned, even our ancestors' description of the beauty of the buttocks was associated with the admiration of the long curves of the entire back and thighs. These curves were recently given names (C, S \& R) by Hoyos [24]. We believe that our new classification is a valuable addition to the foundation set by the work of authors such as Mendieta and Centeno.

\section{Regarding this work-related comparative study:}

The number of patients fulfilling the inclusion criteria in Group (A) (150 patients in 8 years) seems much smaller compared to that of Group (B) (100 patients in 4 years). This is accounted for by the recent increase in the number of patients seeking enhancement of the gluteal area due to refinements of liposuction techniques and fascination by media beauty idols.

Liposuction volumes seem to be significantly higher in Group (B) due to the harvesting of both superficial and deep fat in relation to the membranous layer of the superficial fascia. In Group (A), only the fat deep to the membranous layer of the superficial fascia was harvested (Table 1).

Regarding the volume of fat transfer for both buttocks, Group (A) needed significantly higher volumes to the volumes needed in the Group (B) cases. This volume difference is explained by the fact that in Group (A), the authors used to inject fat tissue to augment the size of the buttocks as a simple aesthetic subunit following previous authors' guidelines, but later in Group (B), they started to 
do a combination of differential augmentation and liposuction according to the need of each aesthetic area (areas 6, 7, 8, 9, 10,11, and 12 in their newly adopted method of evaluation). In Group (B), the authors managed to meet more of the variations in ethnic and personal demands Fig. (2). Getting a good aesthetic outcome with a smaller volume is advantageous, as the rate of transferred fat survival is much better with smaller fat volumes (Table 2).

Seromas and minor burns of the liposuction port were the only complications in this work. The seroma incidence was $6 \%$ and $3 \%$ in Group (A) and Group (B), respectively. The frequency of seroma development was much less in Group (B) due to the act of leaving dependent liposuction ports unstitched at the end of the surgery. The incidence of seromas is higher among high definition liposuction cases in general and even more in cases of ultrasound-assisted liposuction compared to traditional liposuction in the absence of any drainage form [28]. Hoyos advocated the use of open drainage, e.g., corrugated silicon drains, over closed drains of the liposuction areas to avoid seroma development [29]. The liposuction portrelated complications (friction burns and bad scars) were much less in Group (B) as the patients of this group benefited from the appearance of the port protectors in practice. The port protectors were not yet available in practice during the era the authors were operating on Group (A) cases. No major complications were encountered in this series such as major blood loss, skin loss or pulmonary complications (Table 3 ).

The most dangerous complication of fat transfer to the buttocks is pulmonary fat embolism, which occurs mainly due to intramuscular injection of fat [30]. The incidence of mortality is $3 \%$ according to Mofid et al., [30] and in one of each 3000 procedures according to the Multi-Society Task Force for Safety in Gluteal Fat Grafting (ASAPS, ASPS, ISAPS, IFATS, ISPRES), which recently issued a global online warning [30]. According to this warning, it is possible to avoid this tragic complication by injection with larger bore cannulas (larger than $4 \mathrm{~mm}$ ), injection strictly in the subcutaneous tissues and withdrawal before injection, and injection while withdrawing the cannula $[\mathbf{3 0 , 3 1 ]}$. The subject of fat embolization with fat transfer to the buttocks is not the main subject of this work.

The satisfaction rates were high in both groups, but they were better in Group (B) compared to Group (A). In our opinion, this difference is due to the greater flexibility in meeting the variable ethnic, racial and personal aesthetic demands of patients, giving more harmony and balance between the buttocks and buttock-related subunits, e.g., back and lateral thigh, a low complication rate (Table 4). It was noted that a good percentage of the dissatisfied patients in Group (A), who asked mainly for buttock enhancement, were not happy because of residual back rolls after surgery (Table 5).

Pre-operative and post-operative photography were assessed by four senior plastic surgeons from other university. They shared as independent assessors to give an objective opinion regarding results of the patients. The Kappa statistical analysis [22] showed that the agreement between patients' opinion and objective assessment was substantial as regard to results $(\mathrm{K}=0.751)$ of Group (A) and was perfect regarding to Group (B) (0.831).

\section{Conclusion:}

The authors of this work believe that this new analytical tool is a valuable step forward to help achieve results that are more satisfying to patients. The benefits of this tool are as follows:

- It was shown to be versatile enough to meet the demands of patients with different racial body characteristics and even subjective demands.

- It helps the surgeons assess what and where the aesthetic defect is that needs correction by liposuction versus fat transfer, thus helping to remove fat from the undesired areas and shifting it to the areas where increasing fat volume is demanded. A good aesthetic outcome can be achieved, even with relatively smaller volumes of fat tissue.

- It can help surgeons to recognize asymmetry and the appropriate plane for treatment e.g. Fig. (16).

- It helps surgeons to assess their work results and to recognize the poor results in a more objective way e.g. Fig. (14).

- It is better for the greater expectations of the patients nowadays.

- It allows a relatively larger volume of fat tissue for transfer yet lesser volumes needed to obtain good aesthetic outcomes; thus, a better result can be achieved in the case of patients with relatively small fat stores and sparing fat for transfer to other areas if needed, e.g., breasts.

- It is a simple and reproducible method, i.e., taking tissue from identified areas of tissue excess to be added to the identified areas that lack tissue. It allows for liposuction and fat tissue transfer to be combined together, which allows for appropriate management for most patients. 
Despite all the merits of this new analytical tool and the advantages of the innovations in liposuction, some limitations remain. Fat transfer alone will not treat and even may worsen ptosis. Liposuction and fat injections are not an ideal treatment for very thin females with low subcutaneous fat amounts. Additionally, patients with significant weight loss will not benefit from these techniques. The authors of this work are not claiming their analytical algorithm to be perfect, but they believe it to be a valuable step in the aesthetics of the backside of the female body.

\section{Acknowledgement:}

The authors like to acknowledge the efforts of professor Dr. Mohammed Elhaddi-Plastic and Reconstructive Surgery Department, Al-Mansoura University, Egypt and the Department Plastic Surgeons for giving their valuable objective opinion in the assessment of the results of this work.

\section{Conflicts of interest:}

The authors have no conflicts of interest to disclose.

\section{Ethical approval:}

All the procedures performed in this study that involved human participants were in accordance with the institutional and national research committees and with the 1964 Declaration of Helsinki and later amendments or comparable ethical standards. Worth confirming that there was no discrimination between the patients in both groups. Each of the studied groups of patients were managed by the up to date techniques in each group time era. Group (A) data were used in a retrospective manner as a control group for comparison. The authors of this work believe that this approach was the best way to avoid unethical discrimination between patients. All the patients signed an informed consent that included sharing their data in all kinds of scientific studies and scientific publications provided that their human rights are respected. No studies are allowed in the authors' department unless approved by the Department Ethical Committee.

\section{REFERENCES}

1- Centeno R.F.: Gluteal Aesthetic Unit Classification: A Tool to Improve Outcomes in Body Contouring. Aesthetic Surg. J., 26 (2): 200-8, 2006.

2- Kilpatrick H.: Chap 6: Qaysi bn Dharih. In: Kilpatrick H. (ed.). the Great Book of Songs, Compilation of the author's craft in Abul-Faraj Al-Isbahani kitab Al-Aghani. London: Routledge, pp. 142-56, 2003.
3- Hoyos A.E. and Prendergast P.M.: Chap. 15: Female Buttocks. In: Hoyos A.E., Prendergast P.M. (ed.). High Definition Body Sculpturing Art and Advanced Lipoplasty Techniques. New York, Dordrecht, London: Springer Heidelberg, pp. 165-76, 2014.

4- Bartels R.Y., O'Malley J.E., Douglas W.M. and Wilson R.G.: An unusual use of the Cronin breast prosthesis: case report. Plast. Reconstr. Surg., 44 (5): 500, 1969.

5- Gonzalez-Ulloa M.: Gluteoplasty: A ten-year report. Aesthetic Plast. Surg., 15 (1): 85-91, 1991.

6- Cardenas-Camaren L., Lacouture A.M. and Tobar-Losada A.: Combined gluteoplasty: Liposuction and lipoinjection. Plast. Reconstr. Surg., 104 (5): 1524-31, 1990.

7- Cuenca-Guerra R. and Quezada J.: What makes buttocks beautiful? A review and classification of the determinants of gluteal beauty and the surgical techniques to achieve them. Aesthetic Plast. Surg., 28 (5): 340-7, 2004.

8- Mendieta C.G.: Gluteoplasty. Aesthet. Surg J., 23 (6): 441-55, 2003.

9- Pascal J.F. and Le Louarn C.: Remodeling body lift with high lateral tension. Aesthetic Plast. Surg., 26 (3): 22330, 2002 .

10- Vergara R. and Amezcua H.: Intramuscular gluteal implants: 15 years' experience. Aesthet. Surg. J., 23 (2): 8691, 2003.

11- Colwell A.S. and Borud L.J.: Autologous gluteal augmentation after massive weight loss: Aesthetic analysis and role of the superior gluteal artery perforator flap. Plast. Reconstr. Surg., 119 (1): 345-56, 2007.

12- De Pedroza L.V.: Fat transplantation to the buttocks and legs for aesthetic enhancement or correction of deformities: Long-term results of large volumes of fat transplant. Dermatol. Surg., 26 (12): 1145-9, 2000.

13- Atiyeh S.B., Hayek S. and Ibrahim A.: Chap. 9: Gluteal Contouring and Enhancement for the Massive Weight Loss Patient. In: Atiyeh S.B., Costagliola M. (ed.). Body Contouring Following Bariatric Surgery and Massive Weight Loss, Post bariatric body contouring. Free online edition, ISBN: 978-1-60805-238-7, Bentham eBooks, http//medical.dentalbooks.com, pp. 88-101, 2012.

14- Mendieta C.G.: Classification System for Gluteal Evaluation. Clin. Plast. Surg., 33 (3): 333-46, 2006.

15- Mendieta C.G.: Gluteal Reshaping. Aesthetic Surg. J., 27 (6): 641-55, 2007.

16- Roberts T.L. $3^{\text {rd }}$, Weinfeld A.B., Bruner T.W. and Nguyen K.: "Universal" and ethnic ideals of beautiful buttocks are best obtained by autologous micro fat grafting and liposuction. Clin. Plast. Surg., 33 (3): 371-94, 2006.

17- Heidekrueger P.I., Sinno S., Tanna N., Szpalski C., Juran S., Schmauss D., Ehrl D.Ng.R., Ninkovic M. and Broer P.N.: The Ideal Buttock Size: A Sociodemographic Morphometric Evaluation. Plast. Reconstr. Surg., 140 (1): 20e-32e, 2017.

18- Wong W.W.1, Motakef S., Lin Y. and Gupta S.C.: Redefining the Ideal Buttocks: A Population Analysis Plast. Reconstr. Surg., 137 (6): 1739-47, 2016.

19- Markman B. and Barton F.E. Jr.: Anatomy of the subcutaneous tissue of the trunk and lower extremity. Plast. Reconstr. Surg., 80 (2): 248-54, 1987. 
20- Hoyos A.E. and Prendergast P.M.: Chap. 7: Fat Anatomy, Metabolism, and Principles of Grafting. In: Hoyos A.E., Prendergast P.M. (ed.). High Definition Body Sculpturing Art and Advanced Lipoplasty Techniques. New York, Dordrecht, London: Springer Heidelberg, pp. 83-90, 2014.

21- Klien J.A.: The tumescent technique. Anesthesia and modified liposuction technique. Dermatol. Clin., 8 (3): 425-37, 1990.

22- Viera A.J. and Garrett J.M.: Understanding interobserver agreement: The kappa statistic. Fam. Med., 37: 360-3, 2005.

23- Cansanção A.L.: Abstract: Brazilian Buttocks: Fat Grafting Technique Standardization., Plast. Reconstr. Surg. Glob. Open, 4 (9 Suppl): 29-9, 2016.

24- Hoyos A.E. and Prendergast P.M.: Chap. 1: The Human Form As Art: Contours, Proportions, and Aesthetic Ideals. In: Hoyos A.E., Prendergast P.M. (ed.) High Definition Body Sculpturing Art and Advanced Lipoplasty Techniques. New York, Dordrecht, London: Springer Heidelberg, pp. 3-18, 2014.

25- Dixson B.J., Dixson A.F., Bishop P.J. and Parish A.: Human Physique and Sexual Attractiveness in Men and Women: A New Zealand-U.S. Comparative Study. Arch. Sex Behav., 39 (3): 798-806, 2010.
26- Dixson B.J., Sagata K., Linklater W.L. and Dixson A.F.: Male Preferences for Female Waist-to-hip Ratio and Body Mass Index in the Highlands of Papua New Guinea. Am. J. Phys. Anthropol., 141 (4): 620-5, 2010.

27- C.G., Sood A.: Classification System for Gluteal Evaluation Revisited. Clin. Plastic Surg., 45 (2): 159-77, 2018.

28- V.V., Wagh M.S.: Unfavourable outcomes of liposuction and their management. Indian J. Plast. Surg., 46 (2): $377-$ 92, 2013.

29- Hoyos A.E. and Prendergast P.M.: Chap. 19: Post-operative Care. In: Hoyos A.E., Prendergast P.M. (ed.). High Definition Body Sculpturing Art and Advanced Lipoplasty Techniques. New York, Dordrecht, London: Springer Heidelberg, pp. 207-17, 2014.

30- Mofid M.M., Teitelbaum S., Suissa D., Ramirez-Montañana A., Astarita D.C., Mendieta C. and Singer R.: Report on Mortality from Gluteal Fat Grafting: Recommendations from the ASERF Task Force. Aesthet. Surg. J., 37 (7): 796-806, 2017.

31- The Multi-Society Task Force for Safety in Gluteal Fat Grafting (2018) Urgent Warning To Surgeons Performing Fat Grafting To The Buttocks (Brazilian Butt Lift or "BBL") (2018). https://www.surgery.org/sites/default/files/ URGENT-WARNING-TO-SURGEONS.pdf. Accessed 7 June 2019. 